\title{
Motor and sensory conduction in the musculocutaneous nerve
}

\author{
W. TROJABORG \\ From the Laboratory of Clinical Neurophysiology, Rigshospitalet, University Hospital, \\ Copenhagen, Denmark
}

SYNOPSIS Motor and sensory conduction velocity in the musculocutaneous nerve were determined in 51 normal subjects. The maximal velocity from the anterior cervical triangle to the axilla was the same in motor and sensory fibres. The conduction velocity decreased $2 \mathrm{~m} / \mathrm{s}$ per 10 years increase of age. It was $70 \mathrm{~m} / \mathrm{s}$ at $15-24$ years and $58 \mathrm{~m} / \mathrm{s}$ at $65-74$ years. The velocity of the slowest components in sensory fibres was $17 \mathrm{~m} / \mathrm{s}$. Three selected case reports illustrate the diagnostic value of the method.

The musculocutaneous nerve originates from the lateral cord of the brachial plexus at or about the lower border of the pectoralis minor muscle and its fibres derive chiefly from the fifth and sixth cervical nerve roots (Sunderland, 1968). Conduction along motor fibres from the axilla to the brachial biceps muscle has been described by Redford (1958) and from Erb's point to the brachial biceps by Gassel (1964) and Kraft (1972). Nelson and Currier (1969) stimulated the nerve at two sites in seven normal subjects and determined the motor conduction velocity along the fibres to the brachial biceps in the nerve segment between the anterior cervical triangle and the axilla.

The study presented in this report deals with conduction velocity along the musculocutaneous nerve in normal subjects in proximal (fossa supraclavicularis-axilla) and distal segments of motor fibres and in proximal (fossa supraclavicularis-axilla) and intermediate (elbowaxilla) segments of sensory fibres. Three selected case reports are presented to illustrate the usefulness of the method.

\section{METHOD}

Fifty-onesubjects without history, signs, or symptoms of neuromuscular disorders were examined; 20 were between 15 and 34 years old, 18 were 35 to 54 years

(Accepted 27 April 1976.) old, and 13 were 55 to 74 years old. The procedures used for recording motor and sensory conduction were the same as those described for other limb nerves (Buchthal and Rosenfalck, 1966, 1971; Payan, 1969; Trojaborg and Sindrup, 1969; Behse and Buchthal, 1971; Buchthal et al., 1974). In short, motor conduction was determined by stimulating the musculocutaneous nerve at two sites: (1) at the anterior cervical triangle just behind the sternocleidomastoid muscle and approximately $6 \mathrm{~cm}$ above the clavicle, and (2) at the axilla between the axillary artery and the median nerve medially, and the coracobrachialis muscle laterally, just above the level of the tendon of the latissimus dorsi muscle. The electric stimulus, $0.2 \mathrm{~ms}$ in duration, was applied through insulated stainless steel needle electrodes, $0.7 \mathrm{~mm}$ in diameter. The near-nerve electrode, with a bared tip of $3 \mathrm{~mm}$, was adjusted close to the nerve as indicated by a threshold of the muscle action potential of 0.5-1 mA (Trojaborg and Sindrup, 1969). The remote electrode, with a bared tip of $5 \mathrm{~mm}$, was placed at the same level as the near-nerve electrode at a transverse distance of $3 \mathrm{~cm}$. The stimulus was delivered from a constantcurrent stimulator isolated from ground. The maximal stimulus current was 5-7 $\mathrm{mA}$-that is, 10 times the threshold current. The action potentials were recorded with concentric needle electrodes $\left(0.07 \mathrm{~mm}^{2}\right.$ leading-off area, DISA $13 \mathrm{KO}$ 511) placed in the endplate zone and adjusted to the region of maximal response in the brachial biceps muscle. The motor responses and the stimulus current were recorded on two channels of an electromyograph (DISA 13KO511). The conduction time was measured from the onset of the stimulus to the onset of the 
muscle action potential; the amplitude was measured peak-to-peak. The distance between the near nerve stimulating electrodes was measured with an obstetric caliper (Gassel and Diamantopoulos, 1964).

The sensory fibres of the musculocutaneous nerve were stimulated with needle electrodes placed along the nerve where it emerges as the lateral cutaneous nerve of the forearm at the level of the elbow crease. Here it can be palpated just lateral to the tendon of the biceps brachii and medial to the brachioradialis muscles (Fig. 1). The near-nerve electrode was adjusted with the amplitude of the sensory potential recorded at the axilla as indicator. The current pulse was 5-10 mA. Further increase in stimulus current increased neither the amplitude nor the number of slow components of the response. At the axilla and anterior cervical triangle, electrodes positioned by means of the motor threshold were used for recording of sensory potentials. The maximum sensory conduction velocity was determined from the latency to the initial positive peak of the potential; the minimum velocity along sensory fibres was determined when the resolution of the recording was high enough to distinguish potentials $0.05 \mu \mathrm{V}$ in amplitude by means of electronic averaging of 250,500 , or 1000 traces (Buchthal et al., 1974).

TEMPERATURE NEAR NERVE To maintain a temperature of $36-38^{\circ} \mathrm{C}$ along the surface of the limb

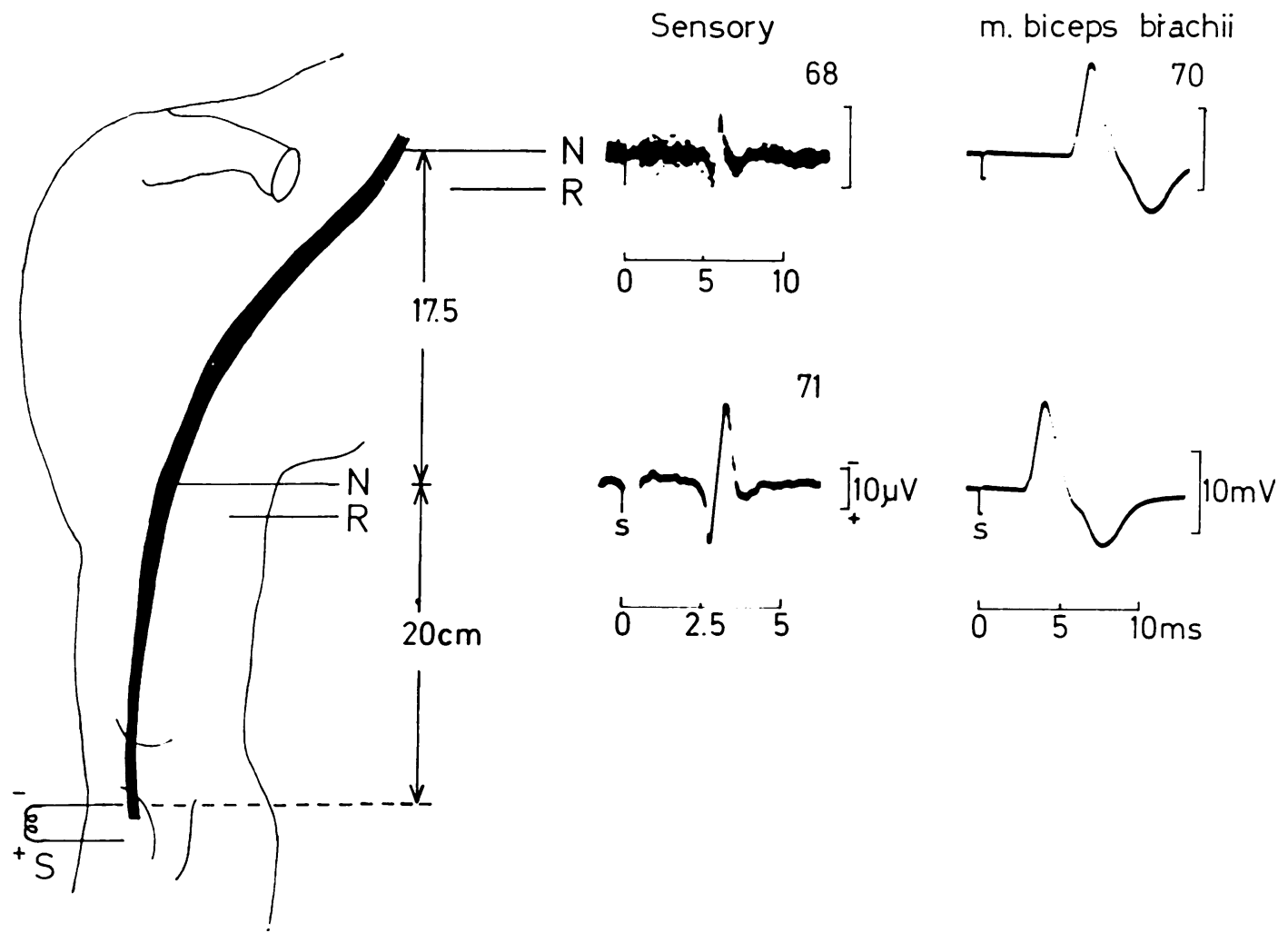

FIG. 1 Motor and sensory potentials evoked by supramaximal stimulation of the musculocutaneous nerve. The nerve was stimulated at the axilla and at the anterior cervical triangle ('Erb's point') and the responses were recorded from the brachial biceps muscle (right). Sensory potentials were evoked by stimulating the lateral cutaneous nerve of the forearm at the elbow $(S)$ and recorded over the nerve at the axilla (lower left) and at 'Erb's point' (upper left, photographic superimposition of 15 traces). The figures above the traces denote the maximal conduction velocity $(\mathrm{m} / \mathrm{s})$ in the segment distal to the point of recording. Time scale in milliseconds $(N=n e a r-n e r v e$ electrode, $R=$ remote electrode). Normal subject, 22 years old. 
corresponding to $35-37^{\circ} \mathrm{C}$ near the nerve, an infra-red heating element $(45 \mathrm{~cm}$ long, $500 \mathrm{~W}$, controlled by a thermocouple on the limb) was placed $20-30 \mathrm{~cm}$ above the upper extremity.

\section{RESULTS}

NORMAL SUBJECTS

MOTOR CONDUCTION The latencies were measured from 51 nerves by stimulating the musculo- cutaneous nerve at the axilla, and at the anterior cervical triangle ('Erb's point', Table 1).

The motor latency increased with the distance between sites of stimulation and recording (Fig. 2). The increase in latency was $0.16 \mathrm{~ms}$ per $\mathrm{cm}$ increase in distance, corresponding to a velocity of $64 \mathrm{~m} / \mathrm{s}$. However, the motor velocity and the amplitude of the evoked response were related to age (Table 2, Fig. 3). With increasing

TABLE 1

MOTOR LATENCY TO M. BICEPS BRACHII (51 SUBJECTS AGED 15-74 YEARS)

\begin{tabular}{|c|c|c|c|c|c|}
\hline \multirow{2}{*}{ Stimulus } & \multirow{2}{*}{ Distance $^{*}(\mathrm{~cm})$} & \multirow{2}{*}{$n$} & \multirow{2}{*}{ Mean $(m s)$} & \multicolumn{2}{|c|}{$95 \%$ limit } \\
\hline & & & & Upper (ms) & Lower (ms) \\
\hline At axilla & 7 & 9 & 2.0 & 2.6 & 1.3 \\
\hline & 9 & 21 & 2.3 & 3.0 & 1.6 \\
\hline & 11 & 31 & 2.6 & 3.3 & 2.0 \\
\hline & 13 & 9 & 2.9 & 3.6 & 2.3 \\
\hline At 'Erb's point' & 25 & 5 & 4.8 & 5.5 & 4.1 \\
\hline & 27 & 17 & $\leq .1$ & 5.8 & 4.4 \\
\hline & 29 & 13 & 5.4 & 6.1 & 4.8 \\
\hline & 31 & 12 & 5.7 & 6.4 & 5.1 \\
\hline & 33 & 4 & 6.0 & 6.7 & 5.4 \\
\hline
\end{tabular}

*Measured wit.ı oest:tric calipers.

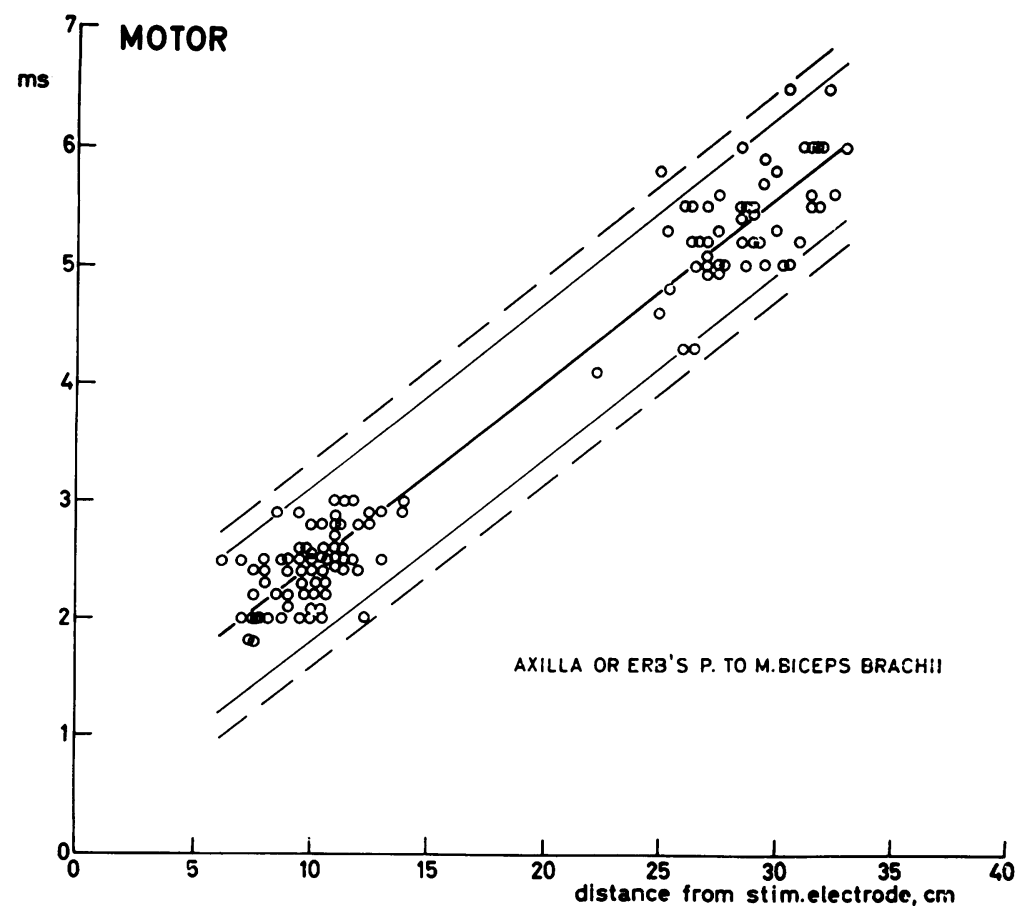

FIG. 2 Latency to the brachial biceps as a function of conduction distance. The thick line represents the regression line, the thin and dashed lines the 95 and $99 \%$ confidence limits, respectively. 
TABLE 2

MOTOR CONDUCTION VELOCITY ALONG MUSCULOCUTANEOUS NERVE FROM ANTERIOR CERVICAL TRIANGLE ('ERB'S POINT') TO AXILLA. AND AMPLITUDE OF EVOKED RESPONSES IN M. BICEPS BRACHII

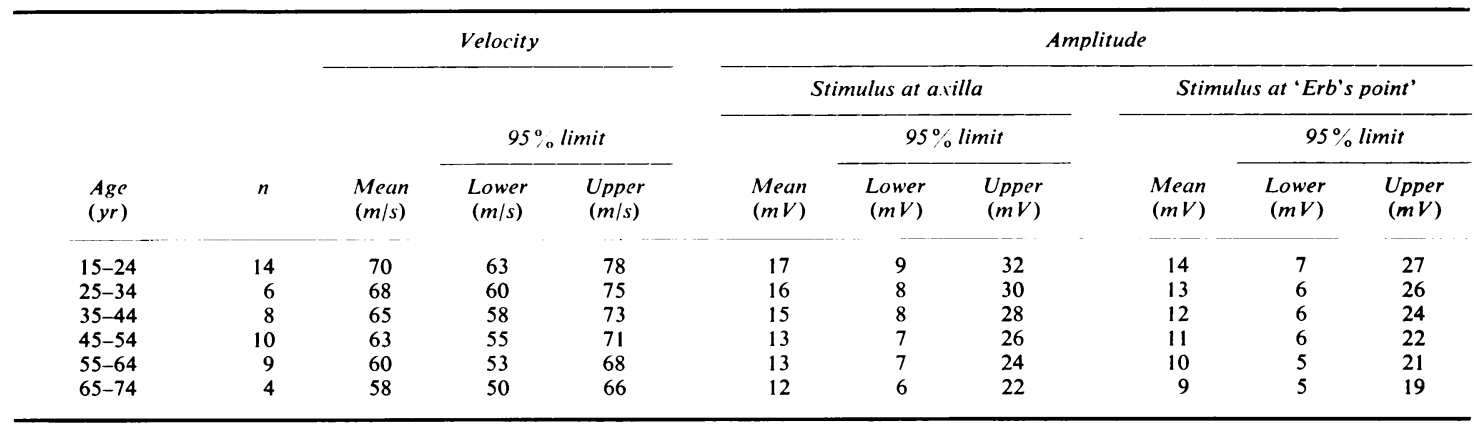

age of the subjects the velocity decreased $2 \mathrm{~m} / \mathrm{s}$ per 10 years of age: the velocity at $15-24$ years being $12 \mathrm{~m} / \mathrm{s}$ faster than at $65-74$ years $(\mathrm{P}<0.001)$. The amplitude of the motor response evoked by proximal stimulation was on average $20 \%$ lower than that evoked by distal stimulation (range $15-25 \%$ ) and the potential amplitudes were smaller in older than in younger subjects (Fig. 3, middle, $\mathrm{P}<0.005$, lower, $\mathrm{P}<0.02$ ).

SENSORY CONDUCTION The maximal sensory conduction velocity was the same in the proximal
(axilla-'Erb's point') and in the intermediate nerve segment (elbow-axilla) and the same as in motor fibres of the musculocutaneous nerve (Table 3). As for motor fibres, the conduction velocity in sensory fibres decreased $2 \mathrm{~m} / \mathrm{s}$ per 10 years increase of age, the velocity at $15-24$ years being $13 \mathrm{~m} / \mathrm{s}$ faster than at $65-74$ years (Fig. 4, $\mathrm{P}<0.001$ ).

The conduction velocity of the slowest components was $17 \mathrm{~m} / \mathrm{s}(\mathrm{SD}, 3.0 \mathrm{~m} / \mathrm{s}, \mathrm{n}=20)$ measured in the segment between elbow and axilla. The potential amplitudes were smaller in older than

TABLE 3

SENSORY CONDUCTION VELOCITY ALONG MUSCULOCUTANEOUS NERVE FROM ELBOW TO AXILLA AND AXILLA TO 'ERB'S POINT' AND AMPLITUDE OF SENSORY POTENTIALS

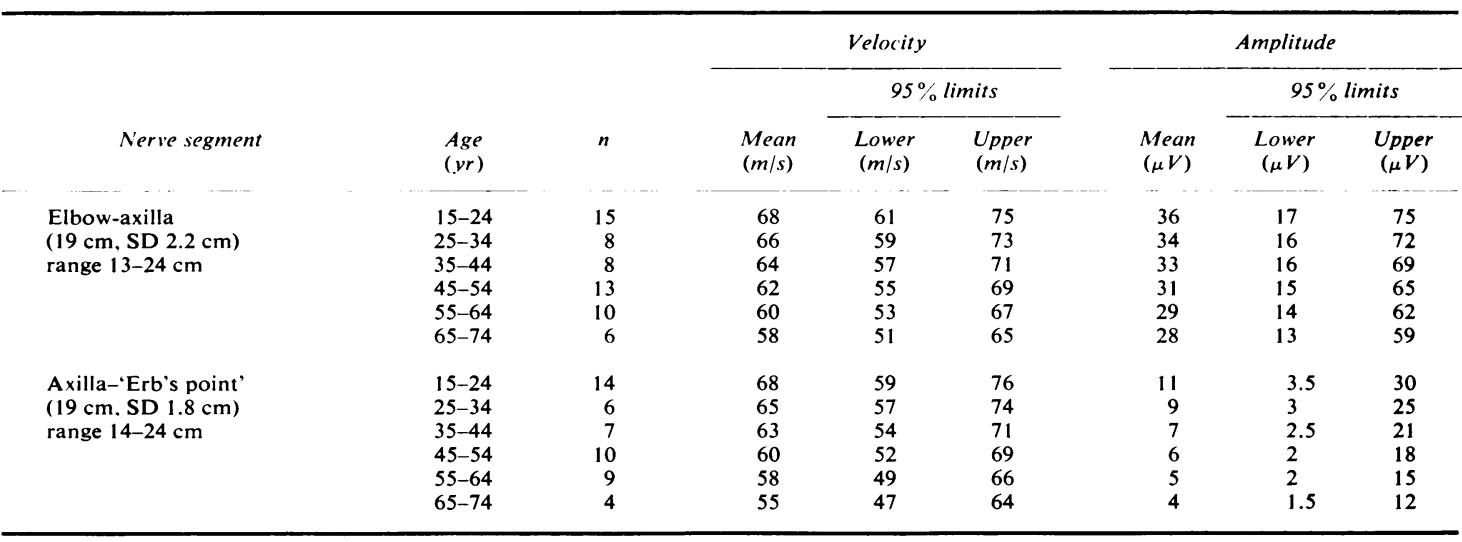




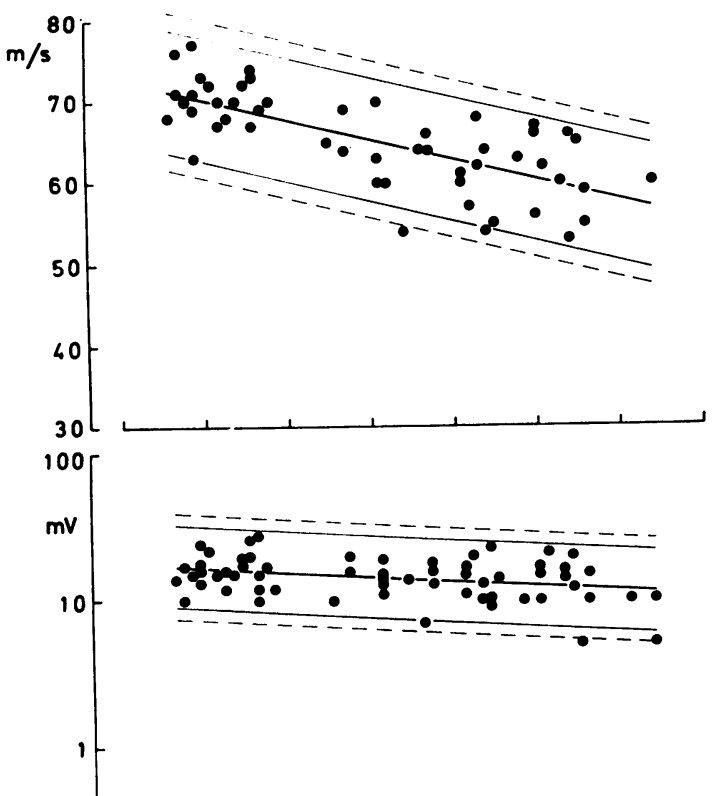

STIM. AXILLA

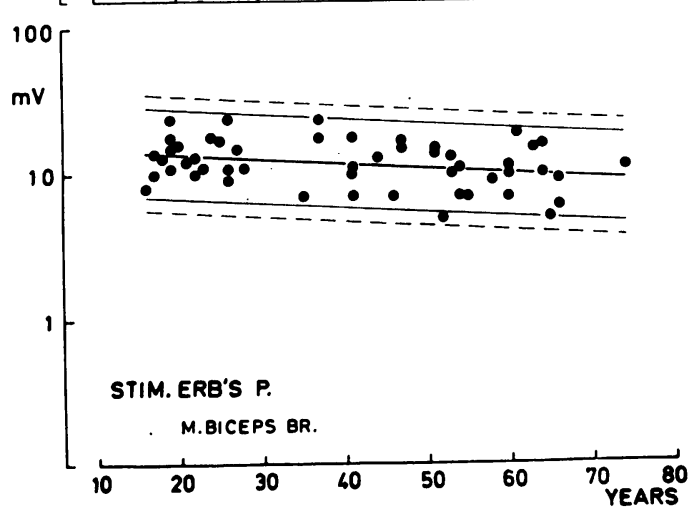

FIG. 3 Motor conduction velocity along the musculocutaneous nerve as a function of age (upper part) and amplitude of the evoked responses in the brachial biceps muscle (log scale, middle and lower part).

in younger subjects (Table 3, Fig. 4). In the older age classes the potentials at the anterior cervical triangle were recorded using electronic averaging of 250 and 500 responses. The amplitude decreased about $75 \%$ from the axilla to 'Erb's point' (range $69-85 \%$ ). The amplitude of the sensory potential recorded at the axilla and at
'Erb's point' decreased about $2 \mu \mathrm{V}$ per 10 years increase of age (Fig. 4, left, $\mathrm{P}<0.06$, right $\mathrm{P}<0.001$ ).

\section{CASE REPORTS}

CASE 1 (EMG 16455) The patient was a 17 year old male who injured his left shoulder when he fell from his motorcycle. On examination there was a fracture of the left clavicle and paralysis of muscles innervated by the superior trunk of the brachial plexus (supraand infraspinatus, deltoid, brachial biceps, and brachioradialis muscles). In addition there was anaesthesia and analgesia corresponding to C5 dermatome. Myelography with iophendylate (Pantopaque) revealed avulsion of the C5 root from the spinal cord.

An EMG performed one month after the injury revealed total denervation of the left deltoid and brachial biceps muscles. Sensory conduction along the musculocutaneous nerve was normal, but motor conduction was abolished. He was reexamined 22 months after the injury. The deltoid and infraspinatus muscles were still totally denervated, clinically and electromyographically, but the force in the brachial biceps was grade 3 (Medical Research Council, 1943) and EMG showed discrete activity in this muscle with an amplitude of $9 \mathrm{mV}$, few denervation potentials, $60 \%$ increased mean action potential duration $(15.7 \pm 1.2 \mathrm{~ms}, \mathrm{n}=20)^{1}$ a five times increased mean amplitude of motor unit potentials $(900 \pm$ $140 \mu \mathrm{V})$ and $20 \%$ polyphasic potentials. Sensory conduction along the musculocutaneous nerve was unchanged whereas motor conduction velocity was $65 \%$ of normal (Fig. 5).

CASE 2 (EMG 19637) This patient was a 5 year old girl who was run over by a garden tractor, sustaining a fracture of the second cervical vertebra and of the left clavicle. On first examination there was paralysis of the left supra- and infraspinatus, deltoid, biceps brachii, and brachioradialis muscles, moderate to severe paresis of forearm flexor and extensor muscles and of the small hand muscles. There was anaesthesiaanalgesia corresponding to $\mathrm{C}_{5-6}$ dermatomes.

EMG confirmed the clinical impression of total denervation of $\mathrm{C}_{5}-\mathrm{C}_{6}$ innervated muscles on three examinations--three weeks, $2 \frac{1}{2}$ months, and eight months after the injury, respectively. In addition, there was evidence of partial denervation of the remaining muscles of the left upper extremity.

No motor responses could be evoked in the paralytic muscles but there were normal sensory action

${ }^{1}$ Here and elsewhere \pm indicates the mean error of the SD. 


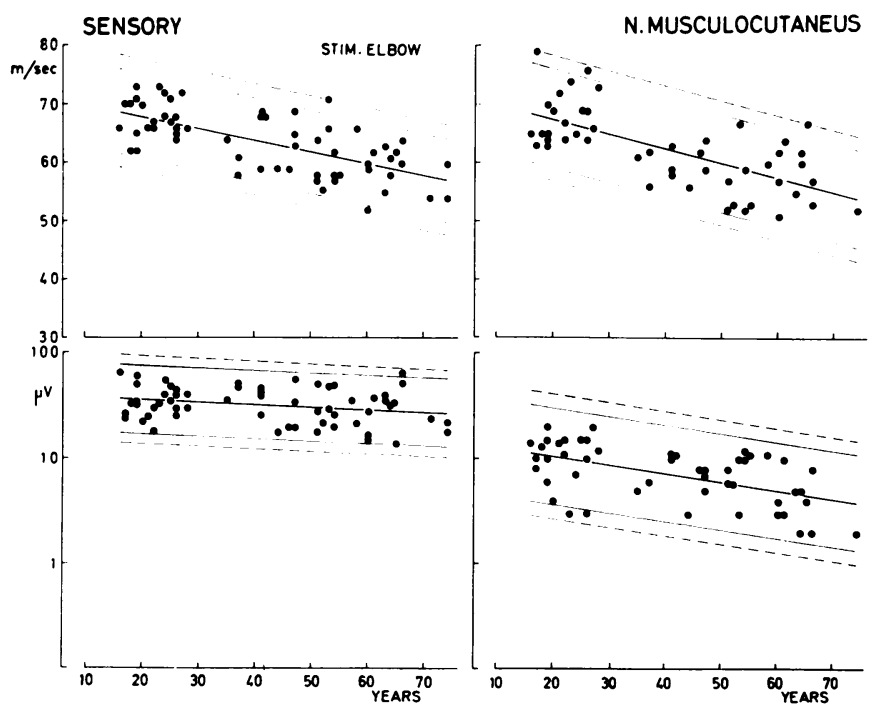

FIG. 4 Sensory conduction velocity along the musculocutaneous nerve as a function of age. Top, left, from elbow to axilla; right, from axilla to anterior cervical triangle. Below, amplitude (log scale) of sensory potentials recorded at axilla (left) and at 'Erb's point' (right).

66

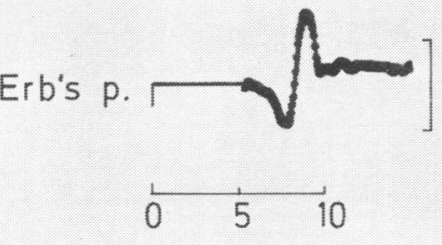

63
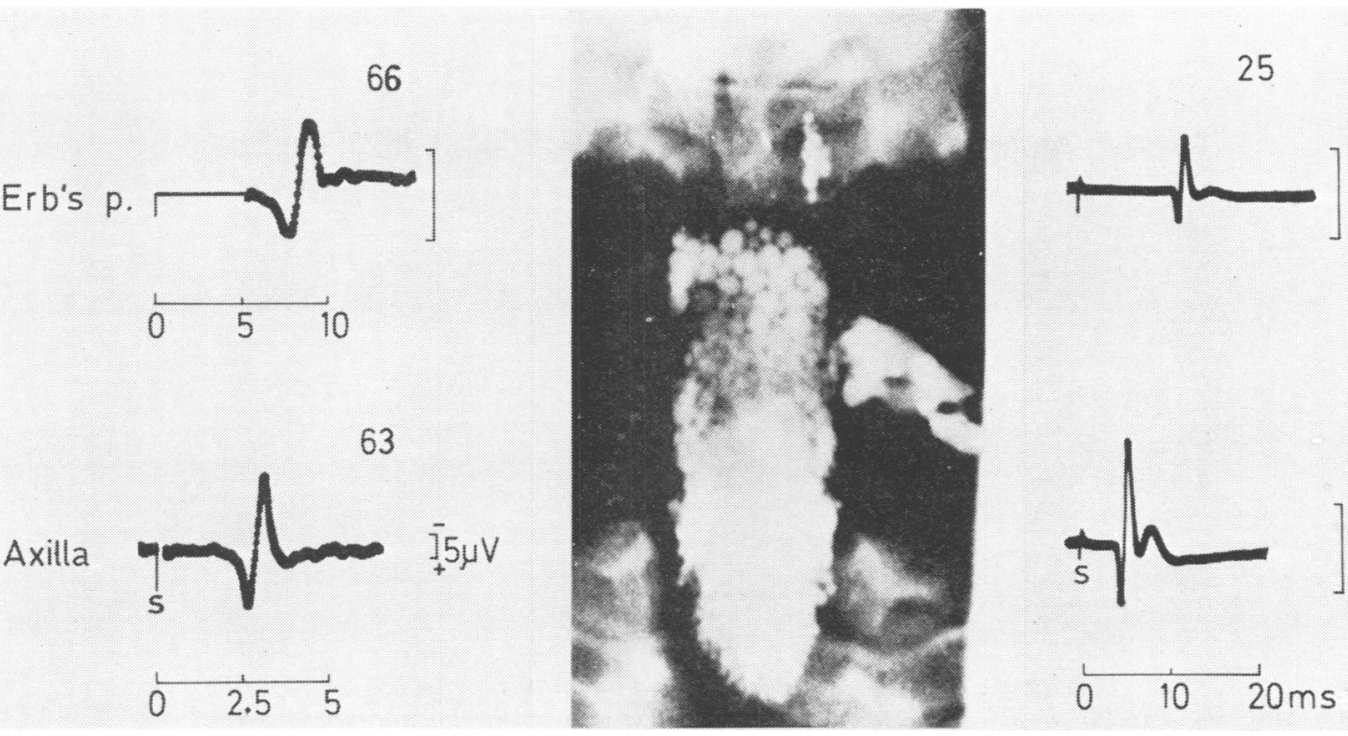

FIG. 5 Left, sensory action potentials evoked by stimulating the left musculocutaneous nerve at the elbow (time scale in ms. Middle, Iophendylate myelogram showing avulsion of the left fifth cervical root. Right, above, responses from the left brachial biceps evoked by stimulation at the anterior cervical triangle; below, at axilla nearly two years after nerve injury. The figures above the traces give the maximal conduction velocity $(\mathrm{m} / \mathrm{s})$ in the segment of the nerve distal to the point of recording. Note the difference between the maximal conduction velocities of motor and sensory fibres. (Case 1, 17 year old male with brachial plexus injury). 
potentials along the axillary and musculocutaneous nerves (Fig. 6) as well as over the median nerve at the wrist when stimulating digit $I$, in spite of anaesthesia. A stimulus of $70 \mathrm{~mA}$ applied to the thumb was not acknowledged. The findings indicate avulsion of $\mathrm{C}_{5}-\mathrm{C}_{6}$ nerve roots. Myelography was not performed.

CASE 3 (EMG 19729) This 19 year old sailor had an isolated left-sided musculocutaneous nerve palsy caused by violent extension of the forearm. On first examination, seven weeks after the onset of palsy, and on the second, five months after nerve damage, the brachial biceps was severely wasted and paralytic. There was anaesthesia and analgesia along the radial margin of the forearm. On both examinations EMG revealed evidence of total denervation of the brachial biceps muscle. Motor and sensory conduction along the musculocutaneous nerve was abolished. At the third examination performed 21 months after the onset of palsy the force of the brachial biceps was graded as 3+ (Medical Research Council, 1943) and the muscle was moderately wasted. Sensory disturbances were still confined to the radial margin of the forearm and consisted of reduced sensation to touch and pin prick.

Electromyography of the brachial biceps muscle showed severe loss of motor units with discrete activity of $5 \mathrm{mV}$ amplitude with full effort. There were denervation potentials in four sites in the muscle. The mean potential duration was $72 \%$ increased $(17.2 \pm$ $1.3 \mathrm{~ms}, \mathrm{n}=23$ ), the mean amplitude of motor unit potentials was $220 \%$ increased $(1.190 \pm 310 \mu \mathrm{V})$ and polyphasic potentials comprised $35 \%$ of all potentials. The latency to the brachial biceps was 2.5 times normal, the amplitude of the evoked motor response was one-fifth of normal. The maximal conduction velocity along sensory fibres was less than half the normal and the slowest fibres conducted at a rate of $6 \mathrm{~m} / \mathrm{s}$ (Fig. 7). The amplitude of the sensory potential was severely reduced, the response being obtained only by electronic averaging of 1000 and 2000 stimuli.

\section{n. musculocutaneus}
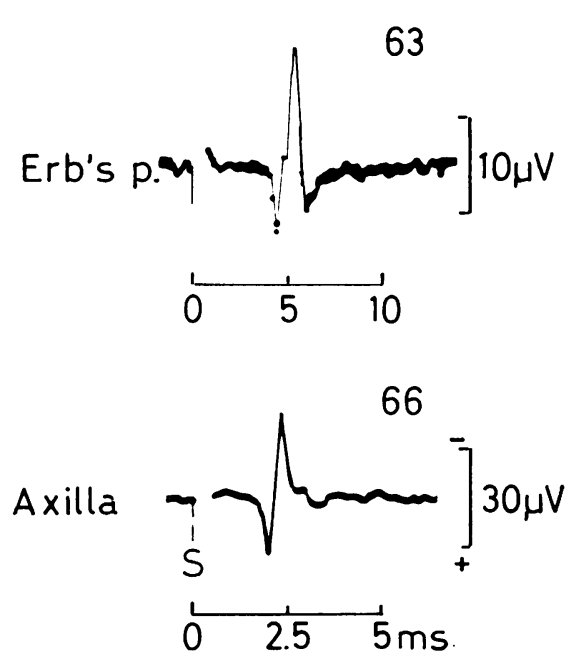

n. axillaris

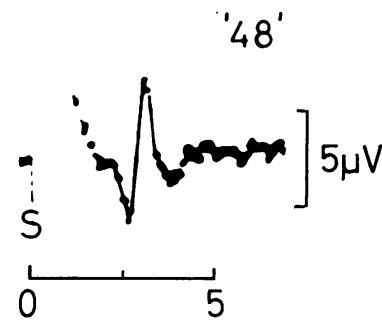

$F, 5 y$

FIG. 6 Left, above and below, sensory action potentials evoked by stimulating the musculocutaneous nerve at the elbow. Right, sensory action potential evoked by stimulating sensory fibres of the axillary nerve in the deltoid region (time scale, $\mathrm{ms})$. The figures above the traces denote the conduction velocity $(\mathrm{m} / \mathrm{s})$ in the segment of the nerve distal to the point of recording. Quotation marks indicate approximation because distance measurement is uncertain due to the course of the axillary nerve. Note normal velocities and amplitudes of sensory potentials in spite of analgesia and anaesthesia corresponding to $C_{5}$ segment (Case 2, 5 year old girl with injury of the brachial plexus). 

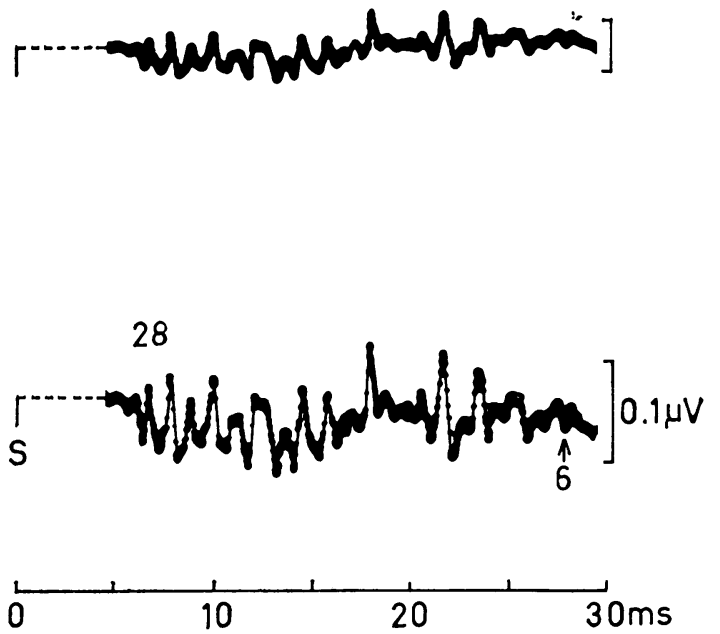

IIG. 7 Sensory action potential recorded at the axilla by stimulating the lateral cutaneous nerve of the forearm at the elbow (stimulus $6 \mathrm{~mA}$ ). Electronic averaging of 1000 stimuli (upper trace) and of 2000 stimuli (lower trace). Slower components were identified as they increased proportional with the calibration signal. The use of a delay before sampling is indicated by the stippled line. The figure above the trace denotes the maximal conduction velocity $(\mathrm{m} / \mathrm{s})$ in the segment of the nerve distal to the point of recording; the figure below the trace gives the minimal conduction velocity $(\mathrm{m} / \mathrm{s})$ from the stimulating near-nerve electrode (S). (Case 3, 19 year old male with an isolated lesion of the musculocutaneous nerve).

\section{DISCUSSION}

The maximum rate of motor conduction in fibres of the musculocutaneous nerve between the anterior cervical triangle and the axilla was similar to the velocities in the radial nerve between the supraclavicular fossa and the elbow (Gassel and Diamantopoulos, 1964) and between axilla and elbow (Trojaborg and Sindrup, 1969). Sensory fibres of the musculocutaneous nerve conducted at the same maximum velocity as motor fibres and the maximum conduction velocity in sensory fibres was the same in the proximal and intermediate segment of the nerve, similar to findings in the median, ulnar, and radial nerves (Buchthal and Rosenfalck, 1966; Trojaborg and Sindrup, 1969).
The maximum motor and sensory conduction velocities decreased with age. The decrease was uniform and rated $2 \mathrm{~m} / \mathrm{s}$ per decade as in the median nerve (Buchthal et al., 1975). Similarly, the amplitude of sensory action potentials decreased with increasing age, the decrease being about $2 \mu \mathrm{V}$ per decade whether the potential was recorded at the axilla or at 'Erb's point'. Moreover, the amplitude decreased about $75 \%$ from axilla to 'Erb's point' which corresponds well with the expected decrease because of the increase in temporal dispersion due to the increase in conduction distance. The velocity of the slowest components in sensory fibres was $17 \mathrm{~m} / \mathrm{s}$, similar to findings in the median and ulnar nerves (Buchthal et al., 1975).

In traction injuries of the brachial plexus the investigation of conduction along motor and sensory fibres of the musculocutaneous nerve might be a valuable supplement to the battery of electrophysiological tests usually applied. Testing of sensory function along the median, radial, and ulnar nerves gives information as to the spinal segments $\mathrm{C}_{6}-\mathrm{C}_{8}$, whereas the musculocutaneous nerve covers the spinal segment $C_{5}$. Thus, avulsion of the $\mathrm{C}_{5}$ root from the spinal cord could be diagnosed in case 1 as a result of the conduction studies along the musculocutaneous nerve. Sensory conduction was preserved in spite of analgesia corresponding to $\mathrm{C}_{5}$ cord segment and motor conduction was abolished. The findings were confirmed by myelography, showing the characteristic dural sac known as a traumatic meningocele (Murphey et al., 1947; Davies et al., 1966). In addition, the total lack of activity in the brachial biceps muscle indicated that $\mathrm{C}_{6}$ fibres had also been damaged. The subsequent partial recovery within the two years of observation suggests regrowth of fibres contained within the $\mathrm{C}_{6}$ root. The electromyographic findings in the brachial biceps together with the result from determination of conduction velocity in fibres to the brachial biceps muscle were consistent with reinnervation after Wallerian degeneration (Trojaborg, 1975).

Similarly, in case 2 with paralysis of muscles innervated by $\mathrm{C}_{5}-\mathrm{C}_{6}$ segments and anaesthesia corresponding to the same segments, the finding of normal sensory potentials along the axillary, musculocutaneous, and median (DI) nerves and absence of evoked responses in the deltoid and 
brachial biceps muscles suggested $C_{5}-C_{6}$ root avulsion. The finding of preserved peripheral sensory conduction in root avulsions of the brachial plexus was first described by Bonney and Gilliatt (1958) and has been confirmed by others (Warren et al., 1969; Buchthal et al., 1975).

Isolated affection of the musculocutaneous nerve is a rare condition. Thus, in the 28 cases of musculocutaneous nerve involvement reported by Worster-Drought in 1921 in his series of 1008 peripheral nerve injuries from the first world war (cited by Sunderland, 1968) in only one was this nerve alone damaged. Osann (1910) surveyed the clinical picture of 19 cases of isolated musculocutaneous nerve palsies published since 1876 , and added one of his own cases; 11 of the 19 cases were of traumatic origin. Seyffarth (1938) was the first to report on electrical responses of single motor units in the brachial biceps muscle in a case of traumatic lesion of the musculocutaneous nerve. Case 3 had such an isolated nerve palsy caused by violent extension of the forearm. As the musculocutaneous nerve runs a straight course and is fixed at the coracobrachialis muscle by branches given off to the biceps and brachialis muscles and at the point where it penetrates the deep fascia at the elbow, violent extension of the forearm might result in an overstretch of the nerve (Sunderland, 1968). In the case presented here, the nerve was totally ruptured. Twenty-one months after the onset of palsy the electromyographic findings were consistent with regeneration after Wallerian degeneration (Trojaborg, 1975). Moreover, the maximum conduction velocity in sensory fibres of the musculocutaneous nerve was reduced $(28 \mathrm{~m} / \mathrm{s})$ and the slowest components conducted at $6 \mathrm{~m} / \mathrm{s}$, far below the normal range. Similar findings have been reported in regenerating nerve fibres after transection (Buchthal et al., 1975).

The author wishes to thank Mrs A. Rosenfalck BS for the statistical evaluation of the normal values.

\section{REFERENCES}

Behse, F., and Buchthal, F. (1971). Normal sensory conduction in the nerves of the leg in man. Journal of Neurology, Neurosurgery, and Psychiatry, 34, 404-414.

Bonney, G., and Gilliatt, R. W. (1958). Conduction after traction lesion of the brachial plexus. Proceedings of the Royal Society of Medicine, 51, 365-367.

Buchthal, F., and Rosenfalck, A. (1966). Evoked action potentials and conduction velocity in human sensory nerves. Brain Research, 3, 122.

Buchthal, F., and Rosenfalck, A. (1971). Sensory potentials in polyneuropathy. Brain, 94, 241-262.

Buchthal, F., Rosenfalck, A., and Behse, F. (1975). Sensory potentials of normal and diseased nerves. In Peripheral Neuropathy. pp. 442-464. Edited by P.S. Dyck, P. K. Thomas, and E. H. Lambert. Saunders: Philadelphia.

Buchthal, F., Rosenfalck, A., and Trojaborg, W. (1974). Electrophysiological findings in entrapment of the median nerve at wrist and elbow. Journal of Neurology, Neurosurgery, and Psychiatry, 37, 340-360.

Davies, E. R., Sutton, D., and Bligh, A. S. (1966). Myelography in brachial plexus injury. British Journal of Radiology, 39, 362-371.

Gassel, M. (1964). A test of nerve conduction to muscles of the shoulder girdle as an aid in the diagnosis of proximal neurogenic and muscular disease. Journal of Neurology, Neurosurgery, and Psychiatry, 27, 200-205.

Gassel, M., and Diamantopoulos, E. (1964). Pattern of conduction times in the distribution of the radial nerve. A clinical and electrophysiological study. Neurology (Minneap.), 14, 222-231.

Kraft, G. H. (1972). Axillary, musculocutaneous, and suprascapular nerve latency studies. Archives of Physical Medicine and Rehabilitation, 53, 383-387.

Medical Research Council (1943). Aids to the Investigation of Peripheral Nerve Injuries, War Memorandum No. 7. HMSO: London.

Murphey, F., Hartung, W., and Kirklin, J. (1947). Myelographic demonstration of avulsing injury of the brachial plexus. American Journal of Roentgenology, 58, 102-105.

Nelson, R. M., and Currier, D. P. (1969). Motor-nerve conduction velocity of the musculocutaneous nerve. Physical Therapy, 49, 586-590.

Osann, E. (1910). Beitrag zur Kenntnis der isolierten Lähmung des N. musculo-cutaneus. Deutsche medizinische Wochenschrift, 36, 832-835.

Payan, J. (1969). Electrophysiological localization o ulnar nerve lesions. Journal of Neurology, Neurosurgery, and Psychiatry, 32, 208-220.

Redford, J. W. B. (1958). Conduction Time in Motor Fibres of Nerves which Innervate Proximal Muscles of Extremities in Normal Persons and in Patients with Neuromuscular Diseases. Thesis: University of Minnesota.

Seyffarth, H. (1938). Electrical responses of single motorunits in the biceps muscle in a case of traumatic lesion of the musculocutaneous nerve. Acta Psychiatrica et Neurologica, 13, 297-311.

Sunderland, S. (1968). Nerves and Nerve Injuries, pp. 1161. Livingstone: Edinburgh.

Trojaborg, W. (1975). Changes in motor unit parameters during reinnervation. (Abstracts) Fifth International Congress of Electromyography, Rochester, Minnesota. Electroencephalography and Clinical Neurophysiology (in press). 
Trojaborg, W., and Sindrup, E. H. (1969). Motor and sensory conduction in different segments of the radial nerve in normal subjects. Journal of Neurology, Neurcsurgery, and Psychiatry, 32, 354-359.
Warren, J., Gutmann, L., Figueroa, A. F., and Bloor, B. M. (1969). Electromyographic changes of brachial plexus root avulsions. Journal of Neurosurgery, 31, 137-140. 